\title{
Strictness of leniency programs and asymmetric punishment effect
}

\author{
Evgenia Motchenkova $\cdot$ Rob van der Laan
}

Published online: 22 June 2011

(C) The Author(s) 2011. This article is published with open access at Springerlink.com

\begin{abstract}
We analyze the impact of leniency programs on the behavior of firms participating in illegal cartel agreements in a two-stage repeated game model. Our approach takes into account asymmetric punishment effect and allows to discuss the design of leniency programs in the setting with asymmetries. The main contribution of the paper is that we consider heterogeneous firms. This heterogeneity results in additional costs in case of disclosure of the cartel, which are caused by asymmetric punishments. Next, following current antitrust rules, we analyze effects of the strictness of leniency programs, which reflects the likelihood of getting a complete exemption from fine even in case many firms self-report simultaneously. Our main conclusion is that leniency programs work better for small companies, since a lower rate of law enforcement is needed in order to induce self-reporting by smaller firms, while big firms are less likely to start a cartel in the first place given the possibility of self-reporting in future. Finally, we analyze optimal enforcement strategies of the antitrust authority and conclude that the authority with limited resources should implement more generous leniency rules the more cartelized the economy is.
\end{abstract}

Keywords Competition policy · Antitrust - Repeated games · Self-reporting · Leniency programs

JEL Classification $\mathrm{K} 21 \cdot \mathrm{L} 41 \cdot \mathrm{C} 72$

\footnotetext{
E. Motchenkova ( $\square)$

Department of Economics, VU University Amsterdam, De Boelelaan 1105, 1081 HV Amsterdam, The Netherlands

e-mail: emotchenkova@feweb.vu.nl

R. van der Laan

Antitrust Department, Netherlands Competition Authority, P.O. Box 16326, 2500 BH The Hague, The Netherlands
} 


\section{Introduction}

Current antitrust enforcement in the US and the EC includes leniency programs as one of the key ingredients, see US Department of Justice $(1993,2008)$ and EC (2006a). Leniency programs grant total or partial immunity from fines to firms collaborating with the antitrust authority by revealing information about existing cartels. This information may be revealed ex-ante before an investigation starts or ex-post during an ongoing investigation. Leniency programs are based on the economic principle that firms, who broke the antitrust law, might report their illegal activities if given proper incentives. In the US, antitrust policy specifies (reduced) fines that are related to the illegal gain and caught cartel members regularly face additional liabilities in the form of private law suites by harmed customers. The EC legislation still has penalties that are proportional to the total annual turnover, which approximates illegal gains in case they are difficult to estimate. Even though it is legally possible in EU countries, private lawsuits are very seldom.

There is some empirical evidence in favor of the modification of the US leniency program in 1993 (see DOJ 1998; Miller 2009). However, theoretical literature has already noted possible negative effects on the expected number of requests for leniency when leniency programs are wrongly designed (see, for example, Motta and Polo 2003; Spagnolo 2004; Ellis and Wilson 2003). We add to this literature a specific notion: companies have different size and operate in several different markets. This heterogeneity triggers asymmetric punishments for different cartel members after conviction. The innovation of our paper is that we present a game theoretical model that takes into account asymmetric punishment effect and discuss the design of leniency programs in the setting with asymmetries.

The problem of how to treat firms if they applied for leniency almost simultaneously or if both applicants provided important information without which case could not be successfully solved has also been raised in recent antitrust practice. These questions are closely related to the issue of asymmetry. Only with asymmetric players one can distinguish between the first and the second reporter. Consequently, in this paper, we study the situation, where the leniency policy of antitrust authority is not only limited to the option of fine reduction for selfreporting firms but also allows different treatment of the first and the second reporter, depending on the environment. ${ }^{1}$ This possibility is imbedded in the current leniency rules of many competition authorities worldwide, but has not been endogenized in theoretical models of leniency so far.

Since, in general, the leniency rules only offer a reduction in the fine calculated on the basis of the affected turnover, but do not take into account other expected costs of admitting illegal behavior that can potentially outweigh the fine, one can question the effect that may be expected from the leniency rules. In general, firms have different size and operate in several different markets. However, they may form a cartel only in some markets. This gives a rise to additional costs in case of disclosure of the cartel caused by an asymmetric punishment effect. When penalty is

\footnotetext{
${ }^{1}$ For example, US leniency guidelines allow fine reductions strictly for the first reporter. While EU leniency rules offer also partial reduction to the second reporter. See also Table 5 in "Appendix 5".
} 
proportional to overall turnover of the company, firms of different size participating in the same cartel agreement will pay different fines. ${ }^{2}$ This effect is asymmetric for firms that are diversified to different extends: that is the smaller is the percentage of turnover in the markets covered by the cartel in relation to total turnover of a firm, the bigger the asymmetric punishment effect is. The same modeling framework can be applied to the case of international cartels, where firms that form a cartel are based in different countries and, consequently, will be subject to different punishment procedures. The important example of this asymmetry concerns international cartels of European and US firms. ${ }^{3}$ In this situation, due to the fact that in US consumers engage in private law suits more often than in Europe, the actual penalty for the US firm would be greater than for the European firm in case a cartel is discovered and information about its existence becomes public. Hence, following the terminology introduced in this paper, US firms are subject to higher asymmetric punishment effect, i.e., they suffer higher costs other than fines in case of disclosure of cartel.

There is an interesting observation from practical antitrust enforcement that some antitrust authorities even employed different (more lenient) format of leniency programs when they were just introduced. For example, the Swiss antitrust authority gave a guaranty of complete or partial exemption to all self-reporting firms in 2004 when leniency program in Switzerland was just introduced and increased the strictness of leniency program later on. ${ }^{4}$ This case suggests that a view by antitrust authorities that leniency programs could be designed differently for different circumstances and different industries (markets). Meaning, in potentially highly cartelized markets, leniency programs should be more lenient and in the markets where cartel formation is less likely they should be more strict. Or, in other words, different rules could be implemented in the countries where leniency programs were just introduced and in the countries that have already long experience practicing leniency programs.

Therefore, there is a need to extend the economic literature on antitrust and leniency programs to take into account both asymmetric punishment effect and structural features of the market when designing and implementing rules of leniency programs. Addressing this problem is the main objective of the paper. But first we provide a review of the related literature.

Malik (1993), Kaplow and Shavell (1994), and Innes (1999) were the first to identify the potential benefits of schemes, which elicit self-reporting by violators, in a very general setting. They conclude that self-reporting may reduce enforcement costs and improve risk-sharing, as risk-averse self-reporting individuals face a certain penalty rather than the stochastic penalty faced by non-reporting violators.

\footnotetext{
${ }^{2}$ It should be noticed that fines imposed according to current EC guidelines (see EC 2006b), which are limited by the amount of $10 \%$ of the total annual turnover of the company, also imply asymmetric punishments. For more details see "Appendix 5" or Wehmhorner (2005).

3 An example of the UCAR international cartel is provided below and it is shown that actual punishments for similar cartel members after the conviction were indeed asymmetric due to the reasons discussed above.

${ }^{4}$ For a more detailed description of the system implemented in Switzerland see the website of Swiss Competition Commission, more specifically, http://www.weko.admin.ch/imperia/md/images/weko/46.pdf.
} 
They consider individual violators rather than a group of violators. In antitrust applications group, violations are analyzed. In that case, introducing an opportunity for whistle-blowing rewarded by fine reduction or even exemption changes, the game played between the antitrust authority and the group of firms. Intuitively, this opportunity should reduce cartel stability by increasing the incentives for firms to reveal the cartel. This conclusion is well established in the literature (see Motta and Polo 2003). However, in the presence of heterogeneity, these incentives change. It is intuitively clear that due to the possibility of asymmetric punishments after a conviction, the cartel members' incentives to deviate and report are also asymmetric. In particular, we will show that the effectiveness of leniency programs is different for different types of companies and depends crucially on the external factors (such as different legal cultures and willingness of consumers to engage in treble damage suits or a number of markets in which a firm operates relative to the number of markets covered by the cartel) if one takes into account asymmetric punishment effect.

Optimal implementation of antitrust policy and leniency programs for cartel enforcement have been analyzed in, e.g., Motta and Polo (2003), Rey (2003), Fees and Walzl (2003), Spagnolo (2004), Motchenkova (2004), Hinloopen (2003, 2006), Chen and Harrington (2007), Chen and Rey (2007), and Harrington (2008). Motta and Polo (2003) show that such programs might have an important role in the prosecution of cartels provided that firms can apply for leniency after an investigation has started. They conclude that, if given the possibility to apply for leniency, a firm might well decide to give up its participation in the cartel in the first place. They find also that leniency saves resources for the authority. Finally, their formal analysis shows that leniency should only be used when the antitrust authority has limited resources, so that a leniency program is not unambiguously optimal. Later, paper by Spagnolo (2004) concludes that courageous leniency programs are closest to the optimal. Spagnolo (2004) uses a game theoretical model to relate a first best "courageous" leniency scheme to a "moderate" leniency scheme to a benchmark case of traditional law enforcement. The courageous program is one in which the reporting party is actually rewarded with a part of the fine paid by the other parties besides receiving amnesty.

Contribution by Feess and Walzl (2003) is one of the few that analyze the effects of leniency programs taking into account heterogeneity of firms. They compare leniency programs in the EU and the US. For that purpose, they construct a stage game with two self-reporting stages, heterogeneous firms with respect to the amount of evidence provided, and ex-post asymmetric information. Differences in leniency programs in the US and Europe include the fine reduction granted for first and second self-reporters, the role of the amount of evidence provided, and the impact of whether the case is already under investigation. The paper by Feess and Walzl (2003) elaborates on the role of asymmetric information to derive the optimal degree of leniency and uses these findings to compare the programs in the US and the EU. The important conclusion of this paper is that any leniency program that does not pay attention to asymmetries between firms leads to a suboptimal cartel deterrence. 
Our paper contributes to the discussed literature on leniency programs by capturing heterogeneity of firms through asymmetric punishment effect. We analyze a situation when a conviction by a competition authority may result in costs other than the fine that are asymmetric. The additional asymmetric costs we will single out are the cost associated with the fact that penalty is calculated on the basis of overall annual turnover of the company and is not restricted to the pure illegal gains in the market corrupted by the cartel agreement. This, what we call asymmetric punishment effect, depends on the size of the firms. The effectiveness of a leniency program largely depends on markets outside the market corrupted by the cartel agreement. This framework is also applicable for analysis of international cartels, where firms are subject to different punishment procedures according to the laws of their countries, or in situations where, following an application for leniency, firms are subject to costs other than the fine itself and where these costs depend on individual characteristics of the firm.

The structure of the paper is as follows. Section 2 provides formal description of the model. In Sect. 3, we solve the model and find subgame perfect equilibrium of the game. Section 4 outlines the optimal enforcement strategies of the authority and strategies that allow to implement the competitive outcome. Section 5 concludes the analysis. In the appendix, we provide comparative analysis of leniency programs in the US and the EC and proofs of the main results.

\section{The model}

We consider a group of firms, which may form a cartel, taking into account the enforcement activity of the antitrust authority. The antitrust authority commits to a certain enforcement policy, which uses leniency programs. Leniency programs grant either complete or partial reduction of fines to the firms, which reveal the existence of a cartel to the antitrust authority. The main innovation of this model, compared to the earlier papers on leniency by Motta and Polo (2003) or Spagnolo (2004), is that we consider heterogeneous firms that have different size and operate in several different markets, but form a cartel in one of the markets. This gives rise to additional costs in case of disclosure of cartel that are caused by an asymmetric punishment effect. This effect can be quantified as follows: firm 1 bears additional costs of $R h_{1}$, while firm 2 suffers additional costs of $R h_{2} . R h_{i}$ denotes additional costs to the company $i$ caused by, e.g., costly treble damage suits by consumers. Another interpretation is related to the size of the firm. If $h_{1}$ and $h_{2}$ denote the total sales in other markets, in which the relevant company does not form a cartel, and $R$ denotes the fraction of total sales in the markets outside of cartel agreement that is paid in fines, then real penalties paid by two equal cartel members would not be identical. ${ }^{5}$ The second innovation of the model is that the leniency policy is not only limited to the option of fine reduction for self-reporting firm but also takes into account possibility of different treatment for the first and second reporter that is

\footnotetext{
${ }^{5}$ In EC guidelines this corresponds to $10 \%(R=0.1)$ of total annual turnover in other markets in which relevant company does not form a cartel.
} 
imbedded in the current leniency rules of many competition authorities worldwide, see, e.g., OECD report (2002) or "Appendix 5".

First, we describe the policy choices of the antitrust authority. Second, we specify the firms' strategies. And finally, we describe the timing of the game.

Enforcement policy: The main goal of the antitrust authority is to prevent cartel formation in the first place. However, if the cartel has already been formed, the antitrust authority aims to discover it at the lowest possible cost. Following Becker (1968), we distinguish two main parameters of enforcement policy: penalty and probability of detection. Hence, the antitrust policy in the presence of leniency programs can be described by the following three parameters.

- The full fines $F \in\left[0, F^{\mathrm{max}}\right]$ for firms that are convicted and that have not cooperated with the authority, where $F^{\text {max }}$ reflects the upper bound that is exogenously given by the law. Following the Becker's argument, in this setup, the fixed fine $F$ will generally be set at $F^{\max }$.

- The reduced fines $f \in[0, F)$ specified by leniency programs. In particular, if only one of the firms reports the cartel, then this firm pays no fine, while the other firm will pay the normal fine, $F$. Moreover, we consider the setup in which all the firms that cooperate can be granted reduced fines $f$. The amount of reduction depends on the circumstances, especially the order of self-reporting and the "value" of additional information. Applying the rules of current European leniency practices discussed in "Appendix 3", the possibility of simultaneous self-reporting by the firms should be ruled out. However, our model is richer and can also predict in the situation where firms self-report simultaneously. To simplify the analysis, we consider a two-firms' game. The first firm to self-report gets complete exemption from the fine, while the second pays the reduced fine, $f=\frac{1}{2} F{ }^{6}$ This setup describes the most strict adherence to the leniency rules. However, we will also consider an alternative setup, where the antitrust authority is less strict and grants complete immunity to both firms in case they self-report almost at the same time. This possibility will be captured by an additional (non-traditional) instrument of antitrust authority, which we call "strictness" of leniency rules and which is denoted by $\alpha$. This parameter reflects the estimated probability that the firm, which self-report almost simultaneously with its rival, gets zero fine.

- The probability of law enforcement by the antitrust authority equals $p \in(0,1]$. This variable can be thought of as an instantaneous probability that the firm is checked by antitrust authority and found guilty. Contrary to Motta and Polo (2003), we assume that whenever the antitrust authority checks the guilty firm, the violation is successfully discovered. Moreover, we assume that $p$ is determined by an exogenous budget of the antitrust authority financed by the government that can be used to promote enforcement, so that $p$ reflects the costs of efforts of antitrust authority put into law enforcement activities.

\footnotetext{
6 These rules are roughly consistent with partial immunity clauses that often apply if more than one cartelist reports. Moreover, Apesteguia et al. (2007) use a similar mechanism to design one of the treatments in their experimental paper, which studies the effects of leniency on the stability of cartel. For currently employed legal rules see also "Appendix 5".
} 
Firms' strategies: We analyze two different collusive strategy profiles of the firms "Enter Cartel and Self-report" and "Enter Cartel and Not Self-report" and one competitive strategy profile "Not Enter the Cartel in the first place".

First, we consider the strategy Enter Cartel and Self-report (ES). The firms decide to enter a cartel agreement. This may give them per period profits $\pi_{m}$ if the cartel is stable. At the next stage of the game, one or both firms choose to report the existence of the cartel to the authority. This allows them to obtain a reduced fine. However, they lose not only extra profits from cartel formation but also incur additional costs due to private law suits by consumers of $R h_{i}$, since information about cartel becomes publicly available. The second collusive strategy is Enter Cartel and Not Self-report (ENS). In this case, the payoff is determined as an expectation of the monopoly gains, $\pi_{m}$ (if cartel is not convicted), and competitive profits, $\pi_{n}$, less the fine and losses due to the asymmetric punishment (if violation is discovered).

The competitive strategy profile is "Not Enter the Cartel in the first place": (NE), which implies that the two-stage game is reduced to one stage. In this case, both firms obtain competitive profits $\pi_{n}$ forever. Note that $0 \leq \pi_{n}<\pi_{m}$.

Timing of the game: The two asymmetric firms play the two-stage game without knowing the action of the rival. At time $t=0$, the antitrust authority sets parameters of enforcement policy: $F$ and $p$. Here, we assume that leniency program is not yet into existence at time $t=0$, and hence, no reduction of fine is possible in case the firm cooperates with the antitrust authority. Consequently, self-reporting is not an option at this stage. However, firms are assumed to know that leniency programs of known parameters will be introduced at the date $t=2$. This setup resembles the policy of most European countries and the US, where traditional antitrust enforcement was generally introduced before the leniency program. ${ }^{7,8}$

Next, at time $t=1$, "the cartel formation subgame" is played. At $t=1$, both firms decide whether to participate in the cartel or stay out and realize the per period associated payoff, respectively, $\pi_{m}$ and $\pi_{n}$. If both firms agree to participate, the cartel is formed and the game continues into second stage. If at least one of the firms decides to stay out, the game stops and both firms obtain competitive profits, $\pi_{n}$, forever. We assume that the existence of a collusive outcome in the industry cannot be observed by the antitrust authority until it starts an investigation in this market.

Further, at time $t=2$, the antitrust authority introduces leniency programs, which allow firms to be exempted from the fine in case of self-reporting. Now those

\footnotetext{
7 See Table 4 in "Appendix 5". For example, in Netherlands LPs came into existence in 2002, 4 years after introduction of traditional antitrust rules. At the EC level antitrust las was introduced in 1958, while leniency programs came into existence only in 1996.

${ }^{8}$ When leniency programs are present from $t=0$, the ((E S),(E S)) equilibrium is dominated by Not Entering ((NE),(NE)) equilibrium. In that case, the game played is not a two-stage game anymore but can be considered as a simultaneous move game, and there are no additional cartel profits realized in the first stage. This implies that in the situations, where the structure of the penalty scheme and leniency programs are both introduced in the beginning of the game $(t=0)$, the solution of the game would follow the same lines as described in Sect. 4 with the simplification that the strategy (E,S) will not be played in equilibrium any more (for any possible parameter values), since it's strictly dominated by the strategy not to enter the cartel in the first place. The detailed proof is provided in "Appendix 4".
} 
firms, which already formed a cartel, have the choice either to keep it secret or report it to the antitrust authority. Hence, at $t=2$, "the revelation subgame" is played, where both firms simultaneously decide whether to report the existence of the cartel to the authority or not. If at least one of them does so, cartel formation stops and both firms obtain $\pi_{n}$. If no firm reveals, the antitrust authority is able to prove them guilty and punish with probability $p \in(0,1]$ in any subsequent period. We assume here that a firm proved guilty does not collude any more, so after being punished firms do not go back to collusion, while in case the cartel has not been revealed or discovered, firms sustain the collusive strategy for at least one more period and obtain monopoly profits, $\pi_{m} \cdot{ }^{9}$ Collusive payoff in this case is given by the following expression $V^{\text {collusion }}=\frac{p\left(\frac{\pi_{n}}{1-\delta}-F\right)+(1-p) \pi_{m}}{1-\delta+\delta p}$, where $\delta$ denotes the discount factor. $^{10}$

The antitrust authority does not take an active part in the game. It only sets policy parameters, $F, f, p, \alpha$, and the rules of leniency programs. As said before, the strictness of the leniency rules is modeled through parameter $\alpha$. A "strict" antitrust authority would give complete exemption from the fine only to the self-reporting firm, which is literally the first to self-report. In this case, the parameter $\alpha$ is close to zero, and the firm that cooperates will almost surely get only partial exemption. Hence, it pays the reduced fine, $f=\frac{1}{2} F$. A "mild" antitrust authority can give complete exemption from the fine to all the firms that cooperated. ${ }^{11}$ In this case, the parameter $\alpha$ is equal to 1 , and every cooperating firm gets zero fine. It speaks for itself that in our model $\alpha$ is only relevant when both firms self-report at the same stage of the game.

It should also be mentioned that under a regular antitrust policy without a leniency program, collusion can be sustained only when the short run gain from undercutting is smaller than the expected loss triggered by the deviation. This loss follows from the fact that cartel profits, $\pi_{m}$, will be replaced by competitive profits, $\pi_{n}$. Hence, collusion under a regular antitrust policy (i.e., when leniency is not available, and only rate of law enforcement and fine are instruments of competition authority) takes place only when the following inequality is satisfied for each firm

\footnotetext{
9 Similar assumption was adopted in Chen and Harrington (2007). In general, there is no consensus in the literature on that. For example, Motta and Polo (2003) employ an opposite assumption. The best approach would be to unify the two assumptions by introducing "cartel culture" parameter, which reflects the probability of renewing cartel agreement after a conviction, as explained in Houba et al. (2008). In our setup under alternative assumption, where firms keep on colluding as long as no cartel member has deviated even after a detection, results of the analysis seem to be qualitatively similar.

10 The complete derivation of this expression is quite easy to show using the recursive formula. Value of the strategy (Enter and Not self-report) (collusive strategy) can be written as $V=(1-p)\left[\pi_{m}+\delta V\right]+$ $p\left[\left(\pi_{n}-R h_{i}-F\right)+\frac{\pi_{n} \delta}{1-\delta}\right]$. Here, with probability $(1-p)$, firms can continue collusion in the next period and with probability $p$ cartel will be discovered in the next period, which implies competitive profits ever after, fine, and losses due to additional punishments. Now, solving for $V$, we obtain that $V=\frac{p\left(\frac{\pi_{n}}{1-\delta}-R h_{i}-F\right)+(1-p) \pi_{m}}{1-\delta+\delta p}$.

11 Recall the example of leniency programs designed by Swiss competition authority in 2004 that has been discussed in introduction.
} 


$$
\frac{p\left(\frac{\pi_{n}}{1-\delta}-F-R h_{i}\right)+(1-p) \pi_{m}}{1-\delta+\delta p}>2 \pi_{m}-p\left(F+R h_{i}\right)+\frac{\delta \pi_{n}}{1-\delta} \quad \text { for } \quad i=1,2 .
$$

Here, $2 \pi_{m}$ reflects the extra profits from undercutting, since we assume there are only two firms in the market. This inequality implies that collusion can arise only when the discount factor is large enough, namely, $\delta \geq \frac{\pi_{m}(1+p)-p \pi_{n}}{(1-p)\left(2 \pi_{m}-\pi_{n}-\left(F+R h_{i}\right) p\right)}$ for $i=1,2$. This condition states that the discount factor required to induce collusion is smaller if either the difference between monopoly profit and competitive profit (the gains of cartel) increases and/or the expected fine (the expected costs following discovery of the cartel) decreases. If this condition is not met, it is more attractive for either of the firms to deviate from the collusive strategy and obtain monopoly profits for one period and then compete for the rest of the game. For the further analysis, we restrict our attention to the case where this condition is met for both firms, which implies that in the absence of leniency programs, the equilibrium state is collusion. Hence, inequality (1) represents a necessary condition for the second stage of the game ("revelation subgame" played at $t=2$ ) to be reached. Another important restriction on the discount factor is $\delta \geq \frac{\pi_{m}}{2 \pi_{m}-\pi_{n}}$, which implies that in the absence of the antitrust policy, collusion would arise in equilibrium. ${ }^{12}$ Note that in this case, the second stage of the game ("revelation subgame") is also automatically reached, since it is implied by $\delta \geq \frac{\pi_{m}(1+p)-p \pi_{n}}{(1-p)\left(2 \pi_{m}-\pi_{n}-\left(F+R h_{i}\right) p\right)}$.

It should be stressed that for any $t>2$, the decisions of both players do not change and payoffs obtained at $t=2$ will be discounted. This is due to the fact that the penalty is fixed, and hence, the environment does not change. ${ }^{13}$ Below, we summarize the timing of the game.

Stage 0: Antitrust authority announces parameters of the penalty scheme, $p$ and $F$. Stage 1: Firms decide whether to be in a cartel or not (once and for all decision). Stage 2a: Antitrust authority introduces leniency program.

Stage 2b: Firms decide whether to self-report or not (once and for all decision). If no self-reporting by both firms is chosen, then repeated game between authority and firms, where authority can discover violation with probability $p$ in each period, is played till infinity.

The discount factor is given by $\delta=\frac{1}{1+r}$, where $r$ is the interest rate. The game tree and players' payoffs are described in Fig. 1.

We now proceed to establish the subgame perfect equilibria of the two-stage game, which is described in Fig. 1, played among firms once the policy parameters are set.

\footnotetext{
12 In the absence of any antitrust enforcement, i.e., when neither fines nor rate of law enforcement can be used, collusion can be sustained only when the short run gain from an unilateral deviation from collusive agreement by undercutting in prices together with competitive profits thereafter is smaller than the payoff from sustaining collusive strategy forever: $\frac{\pi_{m}}{1-\delta}>2 \pi_{m}+\frac{\delta \pi_{n}}{1-\delta} \quad$ for $\quad i=1,2$.

13 The setup with fixed penalties is widely analyzed in the literature (see Motta and Polo 2003; Spagnolo 2004). For the extension of the analysis of antitrust violations, when fines are proportional to illegal gains from price-fixing (or degree of violation), see Motchenkova (2008), or Motchenkova and Kort (2006). In the setup with proportional penalties, the process is not stationary, environment changes over time, and then, it is necessary to introduce an additional state variable for accumulated illegal gains.
} 


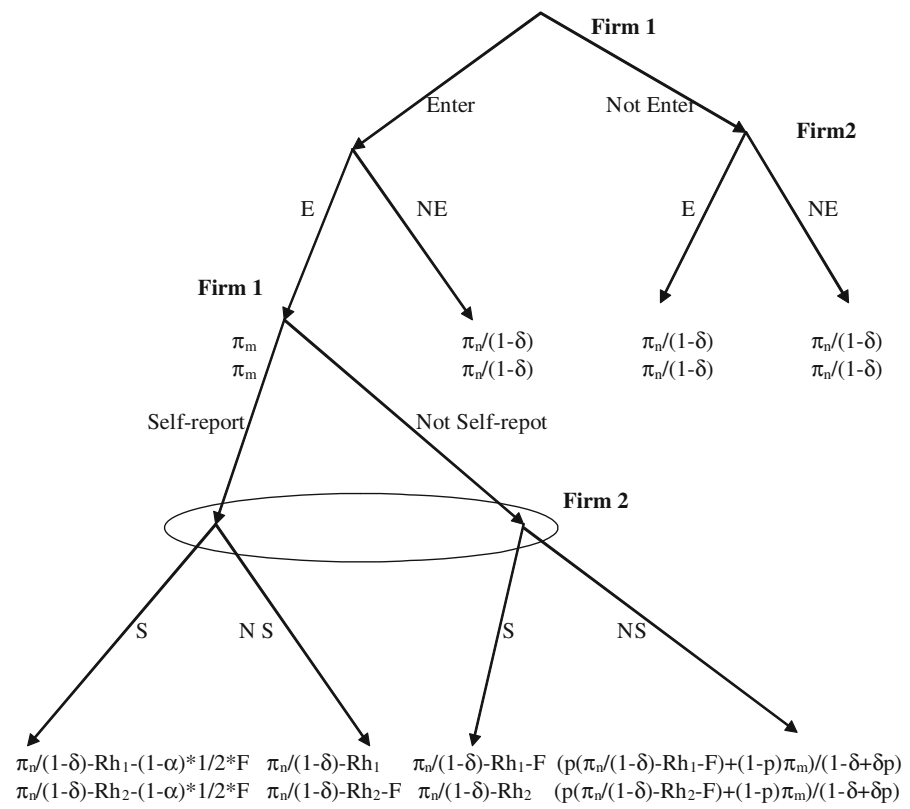

Fig. 1 Game tree and players' payoffs

\section{Solution of the game}

\subsection{Solution of "revelation subgame"}

To find the subgame perfect equilibria of the game, consider first the "revelation subgame", which is played in stage 2 . In case of almost simultaneous self-reporting, a firm $i$ gets a payoff of $\frac{\pi_{n}}{1-\delta}-R h_{i}-\frac{(1-\alpha)}{2} F$. This expression reflects the current EU rules that the first firm to self-report gets complete exemption from the fine, while the second pays the reduced fine, $f=\frac{1}{2} F$, see EC (2006a). Given that the other firm self-reports at approximately the same time, the probability to be the first to report and get zero fine is $\alpha$. However, there is also a chance $(1-\alpha)$ that another firm is the leader in the "race to the court". If a firm $i$ does not self-report but the other firm does, then this firm receives a payoff of $\frac{\pi_{n}}{1-\delta}-R h_{i}-F$, while the other firm is granted complete leniency and obtains $\frac{\pi_{n}}{1-\delta}-R h_{j}$. Note that there is still a negative asymmetric punishment effect, due to, for example, private law suits by consumers after information about the cartel becomes public. Finally, if no firm self-reports, each firm receives an expected payoff $\frac{p\left(\frac{\pi_{n}}{1-\delta}-R h_{i}-F\right)+(1-p) \pi_{m}}{1-\delta+\delta p} .{ }^{14}$ The normal form of the simultaneous move "revelation subgame" is given in Table 1.

The normal form matrix game described in Table 1 can have either one or two pure strategy Nash equilibria depending on parameter values. The strategy $(S, S)$, in which all firms choose to self-report, is always a Nash equilibrium for any values of

\footnotetext{
$\overline{14}$ The complete derivation of this expression was provided in footnote 10 of Sect. 2.
} 
Table 1 The normal form of the simultaneous move "revelation subgame"

\begin{tabular}{lll}
\hline firm 1 & firm 2 & \\
\cline { 2 - 3 } & Self-report (S) & Not self-report (NS) \\
\hline Self-report (S) & $\frac{\pi_{n}}{1-\delta}-R h_{1}-\frac{(1-\alpha)}{2} F, \frac{\pi_{n}}{1-\delta}-R h_{2}-\frac{(1-\alpha)}{2} F$ & $\frac{\pi_{n}}{1-\delta}-R h_{1}, \frac{\pi_{n}}{1-\delta}-R h_{2}-F$ \\
Not self-report (NS) & $\frac{\pi_{n}}{1-\delta}-R h_{1}-F, \frac{\pi_{n}}{1-\delta}-R h_{2}$ & $\frac{p\left(\frac{\pi_{n}}{1-\delta}-R h_{1}-F\right)+(1-p) \pi_{m}}{1-\delta+\delta p}, \frac{p\left(\frac{\pi_{n}}{1-\delta}-R h_{2}-F\right)+(1-p) \pi_{m}}{1-\delta+\delta p}$ \\
\hline
\end{tabular}

parameters of the model. The tuple (Not Self-report, Not Self-report), or $(N, N)$, is the second pure strategy Nash equilibrium if the following condition holds $\frac{p\left(\frac{\pi_{n}}{1-\delta}-R h_{i}-F\right)+(1-p) \pi_{m}}{1-\delta+\delta p} \geq \frac{\pi_{n}}{1-\delta}-R h_{i}, i=1,2$. Moreover, when the above inequality holds, the $(N, N)$ equilibrium also Pareto dominates the $(S, S)$ equilibrium, since then $\frac{p\left(\frac{\pi_{n}}{1-\delta}-R h_{i}-F\right)+(1-p) \pi_{m}}{1-\delta+\delta p} \geq \frac{\pi_{n}}{1-\delta}-R h_{i}-\frac{(1-\alpha)}{2} F$ is also satisfied. The last inequality implies that for the class of parameter values with sufficiently low rate of law enforcement, i.e., $p \leq \frac{\pi_{m}-\pi_{n}+R h_{i}(1-\delta)+\frac{(1-\delta)(1-\alpha)}{2} F}{\pi_{m}-\pi_{n}+R h_{i}(1-\delta)+\left(1-\frac{\delta(1-\alpha)}{2}\right) F}$, the normal form matrix game in Table 1 might have two pure strategy Nash equilibria, where $(N, N)$ equilibrium is Pareto-dominant and, hence, will be chosen. ${ }^{15}$ For another class of parameter values, namely when the above inequality is reversed (i.e., condition in (2) is satisfied), $(S, S)$ is the unique Nash equilibrium of the normal form game in Table 1. This implies that self-reporting can be sustained in equilibrium if the following condition holds:

$$
p>\frac{\pi_{m}-\pi_{n}+R h_{i}(1-\delta)+\frac{(1-\delta)(1-\alpha)}{2} F}{\pi_{m}-\pi_{n}+R h_{i}(1-\delta)+\left(1-\frac{\delta(1-\alpha)}{2}\right) F}=p^{*}\left(F, h_{i}, \alpha\right) \quad \text { for } \quad i=1,2
$$

It is easily verified that for player $i$ the payoff from self-reporting is strictly greater than the payoff from keeping the cartel secret, only when $p>p^{*}\left(F, h_{i}, \alpha\right) .{ }^{16}$ Only if $\frac{\pi_{n}}{1-\delta}-R h_{1}-\frac{(1-\alpha)}{2} F>\frac{p\left(\frac{\pi_{n}}{1-\delta}-R h_{i}-F\right)+(1-p) \pi_{m}}{1-\delta+\delta p}$ for $i=1,2$, then $(S, S)$ is the equilibrium outcome of the "revelation subgame", and hence, (Enter and Selfreport) outcome will be preferred by both firms over (Enter and Not Self-report) outcome in the two-stage game. Therefore, following Pareto-dominance criterion, firms self-report in the second stage only if $p>p^{*}\left(F, h_{i}, \alpha\right)$. This gives us the first incentive compatibility constraint. We represent it in Fig. 2 by the line $p^{*}$, which plots $\alpha(p)$ as a convex decreasing function of $p$ in the $(p, \alpha)-$ space.

\footnotetext{
15 The notion of Pareto-dominant equilibrium is well established in the literature (see, for example, Fudenberg and Tirole (1991) pp. 20-22). Following their arguments, players will coordinate on the Pareto-dominant equilibrium if they are able to talk to one another before the game is played and agree to play highest payoff equilibrium in case of multiple Nash Equilibria. And since firms are perfectly rational payoff maximizing agents, there is no reason for them to deviate from this agreement later on.

${ }^{16}$ We assume here that $(S, S),(S, N)$, or $(N, S)$, which lead to self-reporting outcome in the second stage of the game, can only be chosen when both inequalities $\frac{p\left(\frac{\pi_{n}}{1-\delta}-R h_{i}-F\right)+(1-p) \pi_{m}}{1-\delta+\delta p}<\frac{\pi_{n}}{1-\delta}-R h_{i}$ and $\frac{p\left(\frac{\pi_{n}}{1-\delta}-R h_{i}-F\right)+(1-p) \pi_{m}}{1-\delta+\delta p}<\frac{\pi_{n}}{1-\delta}-R h_{1}-\frac{(1-\alpha)}{2} F$ are satisfied. This implies that $p$ must be greater than $p^{*}\left(F, h_{i}, \alpha\right)$. This assumption is equivalent to employing pareto-dominance criterion or, in other words, choosing an outcome on the pareto frontier.
} 

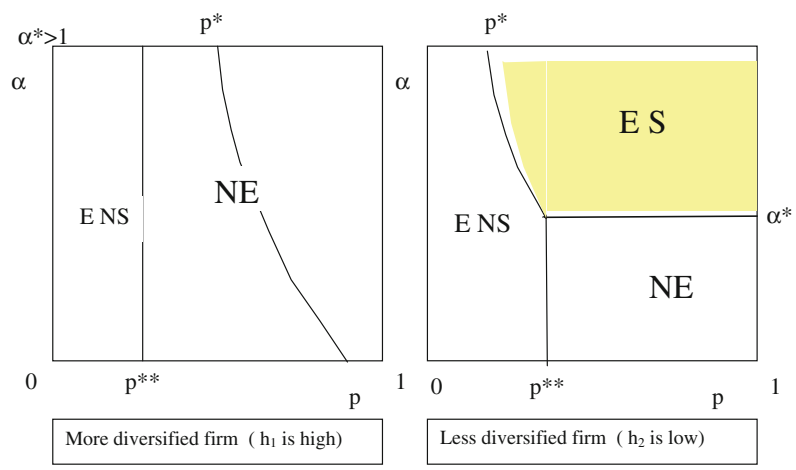

Fig. 2 Incentive compatibility constraints for two types of firms

In addition, comparative statics of the behavior of $p^{*}\left(F, h_{i}, \alpha\right)$ with respect to the main parameters of the model shows that

$$
\frac{\partial p^{*}\left(F, h_{i}, \alpha\right)}{\partial h_{i}}>0, \frac{\partial p^{*}\left(F, h_{i}, \alpha\right)}{\partial F}<0, \frac{\partial p^{*}\left(F, h_{i}, \alpha\right)}{\partial \alpha}<0 .
$$

The first inequality is a result of incorporating the level of asymmetries in punishments. The bigger the asymmetric punishment effect (or the higher the turnover from markets not cartelized compared to total turnover) the bigger the incentives for the firm to abstain from self-reporting. Since a bigger threshold probability $p^{*}\left(F, h_{i}, \alpha\right)$ implies that greater efforts from antitrust authority, in terms of increasing the rate of law enforcement, are needed in order to induce the selfreporting by this firm. The second inequality in (3) reflects the usual trade-off between the probability and severity of punishment extensively discussed in Becker (1968) and in Garoupa (1997, 2001). The third inequality in (3) implies that the uncertainty of the firms about getting the first prize (or, in other words, strictness of the rules for leniency, ${ }^{17}$ which can grant the complete exemption from the fine only to one firm (the US system)) actually reduces the incentives for both types of the firms to self-report.

\subsection{Solution of "cartel formation subgame"}

Now we move on to the decision taken by the firms in stage 1 of the game. For each firm, we have to calculate the discounted sum of profits if firms form a cartel and compare it with the discounted sum of profits in case the cartel is not formed. This comparison has to be done for both cases: when firms decide to self-report in the second stage of the game and when they prefer to continue the cartel.

First, we consider the betrayal scenario where one or both firms choose the strategy Enter Cartel and Self-report, which we denote (E S). According to the

\footnotetext{
17 We refer here to the current US Leniency rules. See Table 3 in "Appendix 3". These rules correspond to low $\alpha$ in our setting, which means that there is very high uncertainty for the firms about getting the first prize. From the third inequality in (3) it follows that in this case the threshold probability $p^{*}\left(F, h_{i}, \alpha\right)$ is maximal and hence, the incentives for the firms to self-report are reduced.
} 
analysis of the previous section, this strategy can arise when $p>p^{*}\left(F, h_{i}, \alpha\right)$ for $i=1$ or $i=2$, or both. In case both firms self-report in the second stage of the game, the expected payoff for each firm includes the collusive profits obtained at $t=1$ plus the expected payoff from simultaneous self-reporting at $t=2$, derived in the previous sub-section, and is given by the following expression ${ }^{18}$ :

$$
V_{E S}=\frac{\pi_{m}}{\delta}+\frac{\pi_{n}}{1-\delta}-R h_{i}-\frac{(1-\alpha)}{2} F
$$

However, when no agreement about cartel formation is reached, the discounted payoffs for both firms, evaluated at $t=2$, are given by $V_{N E}=\frac{\pi_{n}}{\delta(1-\delta)}$.

Collusion and self-reporting will arise if $V_{E S}>V_{N E}$, that is, if the following condition is satisfied:

$$
\frac{\pi_{m}-\pi_{n}}{\delta}-R h_{i}-\frac{(1-\alpha)}{2} F>0
$$

This implies that the value of the parameter $\alpha$ that is necessary in order to ensure that the cartel is not formed should satisfy:

$$
\alpha<\alpha^{*}\left(h_{i}, F\right)=\frac{2 R h_{i} \delta+F \delta-2\left(\pi_{m}-\pi_{n}\right)}{\delta F}, \quad i=1 \text { or } 2 .
$$

This expression provides the second incentive compatibility constraint, which is represented in Fig. 2 by the horizontal line $\alpha^{*}$. Note that three considerably different solutions can arise depending on the parameter values of the model. When $2 R h_{i} \delta+$ $F \delta>2\left(\pi_{m}-\pi_{n}\right)>2 R h_{i} \delta$, we obtain from (6) that $0<\alpha^{*}\left(h_{i}, F\right)<1$, and then, the graph in the right part of Fig. 2 applies. When $2\left(\pi_{m}-\pi_{n}\right)<2 R h_{i} \delta$, we obtain from (6) that $\alpha^{*}\left(h_{i}, F\right)>1$, and then, the incentive compatibility constraints and SPNEs of the game are represented by the graph in the left part of Fig. 2. The third possibility is when $2 R h_{i} \delta+F \delta \leq 2\left(\pi_{m}-\pi_{n}\right)$, so that $\alpha^{*}\left(h_{i}, F\right) \leq 0$. In this case, the equilibrium with no collusion will be lost. The competitive outcome will not arise in equilibrium for any parameter values. The intuition behind this result refers to the fact that when the losses to the firm both due to the fine imposed and due to the additional asymmetric punishments are not high enough, the leniency programs can, actually, have an adverse effect. Too low fines can lead to an outcome were all the firms will participate in a cartel agreement and then depending on the size of relative gains and losses reveal it or keep it secret.

The expression (5) implies that the higher the asymmetric punishment effect, $R h_{i}$, the less likely this inequality will hold. Hence, a bigger firm, which operates in many markets, would be less willing to enter the cartel agreement in the first place. In other words, for bigger firms, the strategy to form a cartel, and then self-report is more likely to be dominated by a strategy of not entering the cartel agreement in the first stage compared to a smaller firm.

\footnotetext{
${ }^{18}$ To simplify the calculations, we evaluate all the payoffs at time $t=2$. So, we discount payoffs obtained at $t=1$ into second period with the factor $(1+r)=\frac{1}{\delta}$, and payoffs obtained in periods $t>2$ into second period with discount factor $\frac{1}{(1+r)^{t-2}}=\delta^{t-2}$.
} 
We may also notice that the decision of both firms when they choose between the strategy Enter Cartel and Self-report or Not Enter the cartel at all does not depend on the value of $p$ (rate of law enforcement). However, it does depend on other parameters of the model, such as $F$ and $\alpha$. In particular, a higher fine reduces the value of the strategy Enter Cartel and Self-report and increases the incentives for the firms to stay out of the cartel. At the same time, the lower the parameter $\alpha$, which reflects the perceived probability for the firm to be the first to report, or the higher the uncertainty about getting the first prize, the greater the incentives for the firms to stay out of the cartel.

Looking at the first and second incentive compatibility constraint simultaneously, ${ }^{19}$ we obtain that for $\alpha<\alpha^{*}\left(h_{i}, F\right), i=1,2$ firms choose not to enter the cartel in the first place, and for all $\alpha>\alpha^{*}\left(h_{i}, F\right), i=1,2$ and $p>p^{*}\left(F, h_{i}, \alpha\right), i=$ 1,2 firms prefer to collude and then self-report in the second stage of the game. This proves the following lemma.

Lemma 1 For given policy parameters $(F, f, p, \alpha)$, a subgame perfect equilibrium in which firms enter the cartel and self-report exists if $p>p^{*}\left(F, h_{i}, \alpha\right)$ and $\alpha>\alpha^{*}\left(h_{i}, F\right)$ for $i=1,2$.

The outcome of this lemma is depicted in the right part of Fig. 2 by the shaded trapezium. In the left part of Fig. 2, this equilibrium is absent, since for more diversified firms the value of $\alpha^{*}$ is likely to be close to 1 . The right part of Fig. 2 shows that for $p>p^{*}$ and $\alpha>\alpha^{*}$ both firms decide to enter the cartel in the first stage and then, because of the high probability of conviction and the fact that rules of leniency programs are not strict, so that almost surely every cooperating firm gets complete immunity from fine, firms choose to reveal the violation.

Next, we look at the second possible outcome of the stage 2 of the game, where both firms choose not to self-report. This outcome arises under condition $p \leq p^{*}\left(F, h_{i}, \alpha\right)$ for both $i=1,2$. In this case, firms anticipate that neither of them will reveal any information. The expected payoff from playing this strategy for each firm includes the collusive profits obtained at $t=1$ plus the expected payoff from non-cooperation with antitrust authority at $t=2$ and is given by the following $\operatorname{expression}^{20}$ :

$$
V_{E N S}=\frac{\pi_{m}}{\delta}+\frac{p\left(\frac{\pi_{n}}{1-\delta}-R h_{i}-F\right)+(1-p) \pi_{m}}{1-\delta+\delta p} .
$$

Again, when no agreement about cartel formation is reached, the discounted payoffs for both firms evaluated at $t=2$ are given by $V_{N E}=\frac{\pi_{n}}{\delta(1-\delta)}$.

Collusion will arise if $V_{E N S}>V_{N E}$, that is if the following condition is satisfied:

$$
p \leq \frac{\pi_{m}-\pi_{n}}{\delta\left(F+R h_{i}\right)}=p^{* *}\left(F, h_{i}\right) \text { for } \quad i=1,2 .
$$

Comparative statics of (7) with respect to the main parameters shows that

\footnotetext{
19 See the right part of Fig. 2, which reflects the case where the critical value of $\alpha^{*}$ is less than one.

${ }^{20}$ Recall Sects. 2 and 3.1.
} 


$$
\frac{\partial p^{* *}\left(F, h_{i}\right)}{\partial h_{i}}<0, \frac{\partial p^{* *}\left(F, h_{i}\right)}{\partial F}<0 .
$$

The first inequality implies that the bigger the size of the firm (or the higher the asymmetric punishment effect), the smaller the threshold probability $p^{* *}\left(F, h_{i}\right)$, and hence, the easier for antitrust authority to prevent the firm from entering the cartel agreement in the first stage of the game. The second inequality, as above, reflects the usual trade-off between the probability of detection and the severity of punishment.

Expression (7) provides the third incentive compatibility constraint, which implies that the strategy "Enter cartel and Not Self-report" is preferred to not entering by both firms when $p \leq p^{* *}\left(F, h_{i}\right), i=1,2$, see also Fig. 2 . Further, recall the first incentive compatibility constraint, which implies that not self-reporting is preferred to self-reporting in the second stage if $p \leq p^{*}\left(F, h_{i}, \alpha\right), i=1,2$. Combining these two constraints, we obtain lemma 2.

Lemma 2 For given policy parameters $(F, f, p, \alpha)$, a subgame perfect equilibrium in which firms enter the cartel and do not self-report exists if $p \leq p^{*}\left(F, h_{i}, \alpha\right)$ and $p \leq p^{* *}\left(F, h_{i}\right), i=1,2$.

The result of this lemma is quite intuitive. For low values of the rate of law enforcement, the worst outcome for society may arise, i.e., firms collude and keep the cartel secret, even when leniency is introduced.

Figure 2 illustrates the incentive compatibility constraints $\left(p^{*}\left(F, h_{i}, \alpha\right)\right.$, $p^{* *}\left(F, h_{i}\right)$, and $\left.\alpha^{*}\left(F, h_{i}\right)\right)$ for two types of firms. The left part of the figure shows that for more diversified firms (firms with higher sales outside the cartel or firms with bigger asymmetric punishment effect), even in the presence of leniency programs, only two possible outcomes (no collusion and cartel without reporting) can arise. So, for these firms, leniency programs are ineffective. The right part of Fig. 2 illustrates the situation with less diversified firms (firms with lower sales outside the cartel or firms with smaller asymmetric punishment effect). In this case, leniency programs can be effective for some parameter values. Self-reporting outcome, $(E, S)$, arises when parameters $p$ and $\alpha$ are sufficiently high (shaded area in the right part of Fig. 2). Moreover, looking at the right part of Fig. 2, we conclude that for high values of $\alpha$, when leniency programs are less strict, the effectiveness of antitrust enforcement can be improved more easily, since then a lower rate of law enforcement is necessary in order to obtain the second best outcome (Enter and Selfreport).

Finally, based on Lemmas 1 and 2, we can conclude that the following proposition holds.

Proposition 3 Once the policy parameters $(F, f, p, \alpha)$ are set, in the repeated game played by the firms from $t=1$ on, we can describe the Subgame Perfect Equilibrium $(S P E)$ in the $(p, \alpha)$-space as follows:

1. When $\alpha^{*}\left(h_{i}, F\right) \geq 1$ for $i=1,2$, i.e., when $\left(\pi_{m}-\pi_{n}\right)<R h_{i} \delta$ for both firms, the Pareto-dominant SPE is ((E NS), (ENS)) for $\left.p<\min _{i=1,2} p^{* *}\left(F, h_{i}\right)\right)$, while the unique SPE is (NE, NE) otherwise. 
2. When $0 \leq \alpha^{*}\left(h_{i}, F\right)<1$ for $i=1$, 2, i.e., when $R h_{i} \delta+\frac{1}{2} F \delta>\left(\pi_{m}-\pi_{n}\right)>R h_{i} \delta$ for both firms, the Pareto-dominant SPE is $\left(\left(\begin{array}{lll}E & N S),(E & N S))\end{array}\right)\right.$ for $\left.p<\min _{i=1,2} p^{* *}\left(F, h_{i}\right)\right)$ and $p<\min _{i=1,2} p^{*}\left(F, h_{i}, \alpha\right)$, it is $((E S),(E S))$ for $p>\max _{i=1,2} p^{*}\left(F, h_{i}, \alpha\right)$ and $\alpha>\max _{i=1,2} a^{*}\left(F, h_{i}\right)$, while the unique SPE is (NE, NE) otherwise.

3. When $\alpha^{*}\left(h_{i}, F\right)<0$ for $i=1,2$, i.e., when $\left(\pi_{m}-\pi_{n}\right)>R h_{i} \delta+\frac{1}{2} F \delta$ for both firms, the Pareto-dominant SPE is ((ENS),(ENS)) for $p<\min _{i=1,2} p^{*}\left(F, h_{i}, \alpha\right)$, while the outcome with self-reporting arises otherwise.

\section{Proof See "Appendix 1".}

This proposition identifies the regions where the (Enter and Self-report), (Enter and Not Self-report), and (Not Enter) equilibria exist. Clearly, both parameters $p$ and $\alpha$ influence the choice of the non-collusive strategy. Moreover, all three possible outcomes can arise in equilibrium only for intermediate range of profits, i.e., when $R h_{i} \delta+\frac{1}{2} F \delta>\left(\pi_{m}-\pi_{n}\right)>R h_{i} \delta$ for $i=1,2$. For low gains from collusion, when $\left(\pi_{m}-\pi_{n}\right)<R h_{i} \delta, i=1,2$, a SPE where both firms choose to enter and self-report does not exist. While, when gains from collusion are high, $\left(\pi_{m}-\pi_{n}\right)>R h_{i} \delta+$ $\frac{1}{2} F \delta, i=1,2$, a pure competitive SPE does not exist.

\section{Optimal enforcement (implementing the competitive outcome)}

This section provides an analysis of the enforcement strategies of an antitrust authority, which has the aim to prevent cartel formation in the industry. Here, we study the optimal enforcement policy in the game described in Sect. 3 The objective of benevolent antitrust authority is to maximize the discounted consumer surplus less the costs of control. Later, we will also consider the situation when the authority maximizes not only the discounted consumer surplus but also the amount of collected fines. It is generally assumed (see e.g., Motta and Polo 2003) that the costs of control and amount of fines are completely determined by parameter $p$. Hence, the enforcement strategies are determined mainly through the rate of law enforcement, $p$. Further, we assume that the fine is fixed and equals its legal upper bound. However, in our setting, there are two additional instruments that the antitrust authority can use to achieve the no-collusion outcome. One of them is leniency, i.e., the possibility of fine reduction if firms self-report; and the second is the strictness of leniency programs, or the possibility of getting complete exemption from the fine even in case simultaneous self-report occurs. These two instruments influence the amount of collected fines.

First, we consider the objective function of the benevolent regulator, who does not aim at maximization of collected fines. In this case, the objective function of the authority is as follows: $W(p, \alpha)=\max _{p, \alpha}\left\{\frac{C S}{1-\delta}-C(p)\right\}=\frac{C S}{1-\delta}+\min _{p}\{C(p)\}$. This setup is widely used in the literature. See, for example Motta and Polo (2003). In addition, we also provide analysis of different setup, since it reflects better the real practice in some European competition authorities. In the Netherlands, for example, 
objective function of most law enforcement agencies includes maximization of collected fines. In the second setup, as the amount of collected fines also depend on the strictness of leniency programs, the antitrust authority maximizes the following objective function: $W(p, \alpha)=\max _{p, \alpha}\left\{\frac{C S}{1-\delta}-C(p)+p \sum f_{i}(\alpha)\right\}$. In both setups, the aim of the authority is to maximize discounted stream of consumer benefits $\frac{C S}{1-\delta}{ }^{21}$ The authority also wants to minimize the costs of control that are reflected in the term $C(p)$, which serves as a generalized notation for accumulated costs of audit, where discounting is already taken into account. $C(p)$ is assumed to be increasing and concave. In the second setup, we assume that the additional regulator's aim is to maximize the amount of fines. This is reflected in the term $p \sum f_{i}(\alpha)$, which serves as a generalized notation for expected accumulated collected fines. $f(\alpha)$ is assumed to be decreasing and concave function of $\alpha$.

The specific characteristic of our model is that we consider heterogeneous firms, in the sense that they may be subject to different local legislation or their total turnover may differ from the turnover of the market corrupted by the cartel agreement, which implies asymmetric punishments. We point out the following regularities for the threshold probabilities that have been derived above. Assume $h_{1}>h_{2}$, then for the threshold probability determined in the "revelation subgame" the following inequality holds: $p^{*}\left(F, h_{2}, \alpha\right)<p^{*}\left(F, h_{1}, \alpha\right)$. However, for the threshold probability determined in the "cartel formation subgame", the opposite holds: $p^{* *}\left(F, h_{1}\right)<p^{* *}\left(F, h_{2}\right)$. Hence, it is more difficult to enforce self-reporting by bigger firms (that have higher turnover), but at the same time a smaller rate of law enforcement (less policing) is necessary in order to prevent the bigger firm from entering the cartel in the first place.

First, we specify the enforcement technology and calculate welfare gains from implementing outcomes that are best for society. These outcomes maximize the consumer surplus less the costs of control in the first setup. While, in the second setup, they maximize the sum of consumer surplus and collected fines minus costs of control. We assume that imposing the monetary fines and determining the strictness of leniency programs is not costly, while increasing the probability of discovery involves costs. In general, we expect a trade-off not only between the rate of law enforcement (policing) and the amount of imposed fines (fining), but also between the rate of law enforcement (policing) and the rules of leniency programs: increasing the strictness of leniency rules would imply a reduction in the level of policing required to reach a desired level of cartel formation and discovery. However, we will see that this intuitive trade-off does not always work in this direction.

In the further analysis, dead weight losses will approximate losses of consumer surplus due to the fact that the market outcome does not coincide with competitive one. The traditional dead weight loss (DWL) measures the welfare gains associated with a successful intervention that induces a more competitive market equilibrium. We evaluate the welfare gains of antitrust enforcement by comparing the

\footnotetext{
${ }^{21}$ Note that the Consumer Surplus (CS) from cartel deterrence by the Antitrust authority is constant and does not depend on parameters of the model and the policy instruments. It just reflects an increase in consumer welfare due to price reduction from cartel price level to competitive level.
} 
equilibrium outcomes where both firms "do Not Enter", "Enter and Self-report", and "Enter and Not Self-report" to the situation with collusion. Note that the antitrust authority will rank the regions as follows: (NE) gives higher welfare gains than (E S), and (E S) gives higher welfare gains than (E NS). Cartels entail an allocative efficiency loss, and therefore, the antitrust authority aims to deter or break them if they are already formed. In the first case, (NE), cartels are deterred; in the second case, (E S), cartels are broken in the second stage if they happen to be formed in the first stage; in the third case, (E NS), only those cartels, which are investigated, will be broken.

\subsection{Optimal enforcement in the two-stage game}

In this subsection, we identify the optimal policies of the antitrust authority. Recall that the antitrust authority changes its policy throughout the planning horizon in the sense that leniency is introduced later in time than the penalty scheme. We first characterize the optimal policy when the antitrust authority wants to implement each of the three outcomes (NE), (E S), or (E NS). Then, we compare the implementable outcomes and select the best one.

As a general point in all the equilibrium outcomes, it is always optimal to set the fine equal to its legal upper bound since increasing the fines is not costly and allows to obtain more favorable (lower) boundaries for the threshold probabilities for the rate of law enforcement.

In the model described above, savings of dead weight loss $\frac{S D W L}{1-\delta}$ are the welfare gains from the "Not Enter" equilibrium. The welfare gains in case of the "Enter and Self-report" equilibrium are $\frac{S D W L}{1-\delta}-S D W L=\frac{\delta S D W L}{(1-\delta)} \cdot{ }^{22}$ In the "Enter and Not Selfreport" equilibrium, the antitrust authority interrupts collusion only with probability $p$; hence, the welfare gains are $\frac{p \delta S D W L}{(1-\delta)}$. Note that the following inequality holds: $\frac{S D W L}{1-\delta}>\frac{\delta S D W L}{(1-\delta)}>\frac{p \delta S D W L}{(1-\delta)}$. Hence, the most favorable for society outcome is no cartel formation, second best is when firms collude and then reveal the cartel after leniency programs are introduced. The worst for society outcome is "Collude and Not Reveal". Of course, this information is not enough for determination of the equilibrium that maximizes welfare, costs of enforcement and collected fines should be taken into account.

Figure 3 illustrates the optimal policies to implement each of the three outcomes discussed above, if $h_{1}>h_{2}$, i.e., firm 1 is "bigger" or has higher turnover. The solid lines $p_{1}^{*}, p_{1}^{* *}$, and $\alpha_{1}^{*}$ represent the incentive compatibility constraints for the "bigger" firm (that is subject to the higher asymmetric punishment effect), while the dashed lines $p_{2}^{*}, p_{2}^{* *}$, and $\alpha_{2}^{*}$ represent the incentive compatibility constraints for the "small" firm (that suffers less from asymmetric punishment effect). In the right part of Fig. 3, we illustrate the situation where threshold on parameter $\alpha^{*}$ (specified in (6)) is smaller than 1 for both firms. Recall that $\alpha^{*}$ in (6) specifies the upper bound on parameter $\alpha$ such that entering cartel and self-reporting would be less attractive

\footnotetext{
${ }^{22}$ Here, we subtract the DWL in the first stage of the game, when the cartel is formed, from the total savings of DWL from period $t=1$ on, given by $\frac{S D W L}{1-\delta}$.
} 

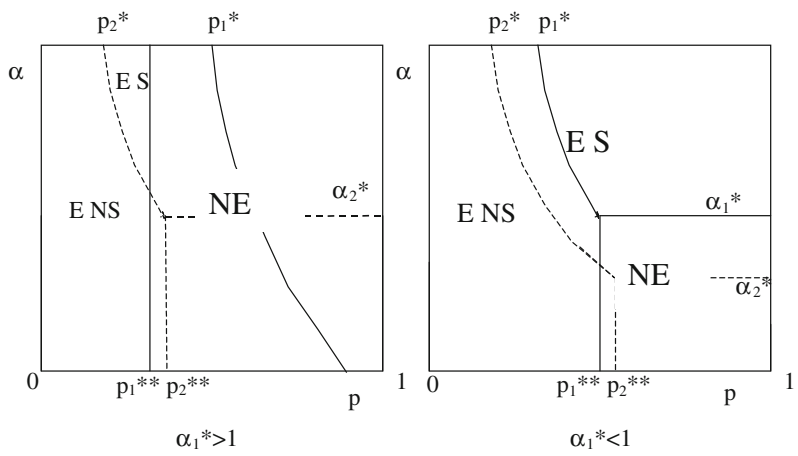

Fig. 3 The optimal policies that implement the (NE), (E S), and (E NS) outcomes. Solid lines represent incentive compatibility constraints for the "bigger" firm, and dashed lines represent incentive compatibility constraints for the "smaller" firm

than staying out of cartel. It is also possible that threshold $\alpha^{*}$ in (6) is greater than 1 for the "bigger" firm. In this case, the left part of Fig. 3 applies and the range of parameter values, for which $(E, S)$ outcome arises, will be reduced considerably. To interpret the figure, we should also note that the $(N E)$ outcome will arise when it is profitable for at least one of the firms not to enter the cartel agreement. The $(E, S)$ outcome will arise when it is attractive to self-report for at least one of the firms. However, the $(E, N S)$ outcome can only arise when entering the cartel agreement and keeping it secret is attractive for both firms. After analyzing incentive compatibility constraints for both types of the firms simultaneously and taking into account the above considerations, we can state the optimal policies that implement the "Not Enter", "Enter and Self-report", and "Enter and Not Selfreport" outcomes. These results are summarized in propositions 4 and 5 .

In the next proposition, we state results for the setup, where the objective function of the antitrust authority is given by $W(p, \alpha)=\max _{p, \alpha}\left\{\frac{S D W L}{1-\delta}-C(p(\alpha))\right\}=\frac{S D W L}{1-\delta}+$ $\min _{p, \alpha}\{C(p(\alpha))\}$. In this case, the benevolent antitrust authority takes into account only the objective of minimizing dead weight loss and reducing the costs of law enforcement. In this setup, the following proposition holds.

Proposition 4 Let $h_{1}>h_{2}$ and the objective function of the antitrust authority is given by $W(p, \alpha)=\max _{p, \alpha}\left\{\frac{S D W L}{1-\delta}-C(p(\alpha))\right\}$.

In the repeated game played by the firms, the optimal policies of antitrust authority that implement the (NE), (ES), and (ENS) outcomes are:

- The optimal policy to implement (NE) sets $p=p_{1}^{* *}$ and $\alpha \in\left[0, \alpha^{*}\left(F, h_{1}\right)\right)$.

- The optimal policy to implement (ES) sets $p=p_{2}^{*}(1)$ and $\alpha=1$.

- The optimal policy to implement (ENS) sets $p=0, \alpha \in[0,1]$ if $\frac{\delta S D W L}{(1-\delta)}-\frac{1}{1-\delta}<0$, or $p=p_{1}^{* *}, \alpha \in\left[0, \alpha^{*}\right]$ if $\frac{\delta S D W L}{(1-\delta)}-\frac{1}{1-\delta} \geq 0$.

Proof See “Appendix 2". 
Based on the results of proposition 4, we can conclude that the first best outcome, i.e., when the cartel is not formed, can be achieved only with a sufficiently high rate of law enforcement, i.e., $p \geq p_{1}^{* *}$, and when the rules of leniency programs are strict enough, $\alpha<\alpha^{*}\left(F, h_{1}\right)$. In other words, in case of simultaneous self-reporting, both firms almost certainly get only partial exemption from the fine. However, if the cartel has already been formed in the first stage, before the leniency program was introduced, the optimal policy that can ensure the second best outcome, i.e., selfreporting in the second stage, should impose a lower rate of law enforcement, $p_{2}^{*}(1)$, and less strict rules of leniency programs, $\alpha=1$. Hence, in general, the enforcement that aims at stopping formation of already existing cartels should be less strict.

The next proposition analyzes the case when the antitrust authority maximizes not only the discounted consumer surplus but also the amount of collected fines. As discussed above, this setup reflects better the current practice at some competition authorities.

Proposition 5 Let $h_{1}>h_{2}$. Given the objective function of antitrust authority: $W(p, \alpha)=\max _{p, \alpha}\left\{\frac{S D W L}{1-\delta}-C(p)+p \sum f_{i}(\alpha)\right\}$, in the repeated game played by the firms from $t=1$ on, the optimal policies are:

- Implementing (NE) outcome sets $p=p_{1}^{* *}$ and $\alpha \in\left[0, \alpha^{*}\left(F, h_{1}\right)\right]$.

- Implementing ( $E S$ ) outcome picks up the point that satisfies the equation $\left(p_{2}^{*}(\alpha)\right)_{\alpha}^{\prime}=-F$, if at this solution $p<p_{1}^{* *}$. Otherwise, if $p>p_{1}^{* *}$, then the optimal policy to implement $(E S)$ sets $p=p_{2}^{*}(1)$ and $\alpha=1$ or $p=p_{1}^{* *}$ and $\alpha=\alpha^{*}$.

- Implementing ((ENS), (ENS)) sets $p=0$ and $\alpha \in[0,1]$ if $\frac{\delta S D W L}{(1-\delta)}-\frac{1}{1-\delta}+2 F<0$, or $p=p_{1}^{* *}$ and $\alpha \in\left[0, \alpha^{*}\right]$ if $\frac{\delta S D W L}{(1-\delta)}-\frac{1}{1-\delta}+2 F \geq 0$.

\section{Proof See “Appendix 3".}

Combining results of propositions 4 and 5, we conclude that under different objective functions results are qualitatively similar. An interesting implication of this analysis is that the regulation by a benevolent authority would not only lead to lower fines for firms and less strict leniency programs but also reduce the costs of law enforcement in some scenarios.

\section{Conclusions}

This paper studies the effects of antitrust enforcement and leniency programs on the behavior of firms participating in cartel agreements. The main innovation is that we consider heterogeneous firms. In general, firms have different size and operate in several different markets. However, they may form a cartel only in one or several markets. This gives rise to additional costs in case of disclosure of cartel caused by an asymmetric punishment effect: when penalty is proportional to overall turnover of the company, firms of different size participating in the same cartel agreement will pay different fines. The same modeling framework can be applied to the case of 
international cartels, where firms that form a cartel are subject to different punishment procedures. $^{23}$

The important example of this asymmetry concerns international cartels of European and US firms. The graphite electrode cartel, UCAR International, which was discovered in 1998, is a good illustration of this point. ${ }^{24}$ In this situation, due to the different legal procedures and the fact that in the US consumers engage in private law suits more often than in Europe, the actual penalty for the US firm would be different from the one for the European firm in case a cartel is discovered and information about its existence becomes public. For example, in the UCAR's case, due to the different systems of fine imposition in the US and Europe, the maximal punishments for similar members of the UCAR International cartel differ almost twice (with the fine of about 100 millon Euro in Europe and the fine of about 200400 million US Dollars for the US leg of the cartel). ${ }^{25}$ This provides strong evidence of "asymmetric punishment effect" in real antitrust practice. Hence, following the terminology introduced in this paper, the US part of the UCAR cartel is subject to higher asymmetric punishment effect, i.e., it suffers higher costs in case of disclosure of cartel. Further, according to the official journal, only the EU leg of the cartel was given a fine reduction due to application for leniency, the US leg did not cooperate with the Department of Justice.

First, we describe the general results, and then, we relate them to the UCAR's case for illustration. We found that the bigger the size of the firm (or the higher the asymmetric punishment effect), the higher the incentives for this firm to keep the cartel secret. Then, greater efforts from the antitrust authority, in terms of increasing the rate of law enforcement, are needed in order to induce self-reporting by this firm. So, leniency programs work better for companies with lower asymmetric punishment effect in the sense that they result in self-reporting by these firms while the rate of law enforcement is lower, which implies lower costs for society. This conclusion seems to be confirmed in the UCAR's case as the EU leg of the cartel decided to apply for leniency, while the US leg of this international cartel chose not to cooperate (possibly due to the threat of higher maximal punishment in case of disclosure).

Further, we conclude that for bigger firms the strategy of not entering the cartel agreement in the first stage of the game is more likely to be preferred over the strategy to form a cartel and then self-report than for smaller firms. The bigger the size of the firm (or the higher additional losses other than fines), the easier it is for the antitrust authority to prevent the firm from entering the cartel agreement in the

\footnotetext{
23 This framework can also be used for an analysis of the effectiveness of leniency programs in situations where disclosure of cartel can lead to any additional costs for the firms different from the fine for violations of competition law itself. Those costs can result from the threat that tax authorities will conduct additional control and possibly frauds connected with cartel agreements will be discovered, or consumers will challenge firms in the courts applying for compensation of private damages.

24 The discussion of the graphite electrode cartel, UCAR International, is adopted from Wehmhorner (2005). More detailed description of fining decisions can also be found in "Appendix 5".

25 For details of how fines are determined, see Tables 6 and 7 in "Appendix 5". It should also be stressed that these are not actual (imposed) fines, but maximal fines that should have been set according to the Sentencing Guidelines in the EU and US in 2001 (before application for leniency by the EU leg and inability to pay by the US leg were taken into account).
} 
first stage of the game. Hence, big firms (or firms for which costs in case of disclosure are higher) are more reluctant to start a cartel in the first place.

Another innovation of this paper is that the enforcement strategies of antitrust authority are determined not only through the rate of law enforcement but also through an additional instrument (called "strictness" of leniency programs), i.e., introducing the possibility of getting complete exemption from the fine even in case many firms self-report simultaneously. We study the impact of the "strictness" of leniency programs on the effectiveness of antitrust enforcement and derive the optimal enforcement strategies. They represent the optimal combination of instruments of the authority: rate of law enforcement and "strictness" of leniency programs. Uncertainty of the firms about getting the first prize (or, in other words, strictness of the rules for leniency, which can grant the complete exemption from the fine only to one firm) reduces the incentives for both types of firms to report. This conclusion also seems to be relevant for the case of UCAR's cartel discussed above. The interpretation is as follows. The US leniency program grants complete exemption only to the first reporter, while the EU leniency rules allow substantial fine reductions for several reporting firms. Hence, EU leniency programs can be viewed as less strict in the terminology offered in this paper. In the US, given stricter leniency programs, there is more uncertainty of the firms about "getting the first prize". According to the analysis performed in this model, this would imply less incentives to self-report. This impact on self-reporting incentives also seems to be confirmed in the UCAR's case, where only the EU member of the cartel decided to apply for leniency.

Another implication of our analysis is that in a highly cartelized economy, where a lot of cartels are already formed, the best strategy for the antitrust authority is to concentrate on policies that increase the incentives to self-report, in particular, increase the fine or reduce the strictness of leniency programs. In other words, the more cartelized the economy, the less strict the rules of leniency programs should be, i.e., complete exemption from fines should be granted to all reporters. ${ }^{26}$ On the other hand, when there are few cartels and leniency is not yet introduced, the antitrust authority should implement the policy that reduces the incentives to enter the cartel in the first place. In this case both, the fine and the strictness of the leniency programs should be increased. Hence, when the economy is not highly cartelized the rules of leniency programs should be stricter, i.e., complete exemption should be granted only to the first reporter.

Finally, we conclude that the optimal enforcement can implement the competitive outcome only when the rate of law enforcement is sufficiently high, and the rules of leniency programs are sufficiently strict. Moreover, the second best outcome, i.e., "Enter cartel and Self-report", can be implemented when the rate of law enforcement is sufficiently high and the leniency programs grant complete exemption from fines to all the firms that cooperate with antitrust authority.

\footnotetext{
26 This conclusion confirms that initial lenient design if Swiss Leniency Programs in 2004, which has been discussed in introduction, could be a clever solution.
} 
Acknowledgments The authors thank Eric van Damme, Peter M. Kort, Giancarlo Spagnolo, anonymous referees, and all the participants of EARIE (2005), ACLE (2006), ESNIE (2006), and EALE (2006) conferences for stimulating discussions and valuable comments.

Open Access This article is distributed under the terms of the Creative Commons Attribution Noncommercial License which permits any noncommercial use, distribution, and reproduction in any medium, provided the original author(s) and source are credited.

\section{Appendix 1: Proof of Proposition 3}

Proof The result of this proposition follows directly from Lemmas 1 and 2 and the fact that all three locuses $p^{*}\left(F, h_{i}, \alpha\right), p^{* *}\left(F, h_{i}\right)$, and $a^{*}\left(F, h_{i}\right)$ intersect in the same point. Simple algebraic calculations confirm that $p^{*}\left(F, h_{i}, \alpha^{*}\right)=p^{* *}\left(F, h_{i}\right)$.

In order to prove this fact, we substitute $\alpha^{*}\left(h_{i}, F\right)=\frac{2 R h_{i} \delta+F \delta-2\left(\pi_{m}-\pi_{n}\right)}{\delta F}$ into the expression for $p^{*}$ in (2) and show that $p^{*}\left(F, h_{i}, \alpha^{*}\right)=p^{* *}\left(F, h_{i}\right)$.

Recall that $p^{*}\left(F, h_{i}, \alpha\right)=\frac{\pi_{m}-\pi_{n}+R h_{i}(1-\delta)+\frac{(1-\delta)(1-\alpha)}{2} F}{\pi_{m}-\pi_{n}+R h_{i}(1-\delta)+\left(1-\frac{\delta(1-\alpha)}{2}\right) F}$.

Hence,

$p^{*}\left(F, h_{i}, \alpha^{*}\right)=\frac{\pi_{m}-\pi_{n}+R h_{i}(1-\delta)+\frac{(1-\delta)\left(1-\frac{2 R h_{i} \delta+F \delta-2\left(\pi_{m}-\pi_{n}\right)}{\delta F}\right)}{\delta F}}{\pi_{m}-\pi_{n}+R h_{i}(1-\delta)+\left(1-\frac{\delta\left(1-\frac{2 R h_{i} i+f+\delta-2\left(\pi_{m}-\pi_{n}\right)}{\delta F}\right)}{2}\right) F}=\frac{\pi_{m}-\pi_{n}}{\delta\left(F+R h_{i}\right)}=p^{* *}\left(F, h_{i}\right)$.

\section{Appendix 2: Proof of Proposition 4}

In order to simplify the calculations, throughout the proof of this proposition, we assume that $C(p)$ is a linear increasing function of the following form $C(p)=\frac{p}{1-\delta}$. Clearly, this implies per period costs of control will be equal to $p$. However, qualitative results would not change, if we assume any increasing and convex functional form.

\section{Proof:}

1. The proof of the first part of the proposition follows straightforwardly from Fig. 3.

2. The second part of the proposition says that a combination of policy instruments of the form $p=p_{2}^{*}(1)$ and $\alpha=1$ would minimize the costs of law enforcement in case the (E S) outcome has to be implemented, and hence, it would maximize the social welfare $W(p, \alpha)=\frac{\delta D W L}{1-\delta}-p(\alpha)$.

Indeed, recall expression (3), which says that $\frac{\partial p^{*}\left(F, h_{i}, \alpha\right)}{\partial \alpha}<0$. This implies that $\min _{\alpha} p^{*}(\alpha)=p^{*}(1)$. Now looking at Fig. 4, we conclude that the optimal policy to implement (E S) sets $\alpha=1$ and $p=\min _{\alpha} p^{*}(\alpha)=p_{2}^{*}(1)$ (point B in Fig. 4).

3. The third part of the proposition follows directly from Fig. 4 and from the objective function of the antitrust authority $W(p, \alpha)=\max _{p} p\left(\frac{\delta D W L-1}{1-\delta}\right)$. This 
implies that $p=0, \alpha \in[0,1]$ if $\frac{\delta D W L}{1-\delta}-\frac{1}{1-\delta}<0$, and $p=p_{1}^{* *}, \alpha \in\left[0, \alpha^{*}\right]$ if $\frac{\delta D W L}{(1-\delta)}-\frac{1}{1-\delta} \geq 0$.

\section{Appendix 3: Proof of Proposition 5}

Again, to simplify the calculations, throughout the proof of this proposition, we assume that $C(p)$ is a linear increasing function of the following form $C(p)=\frac{p}{1-\delta}$. Clearly, this implies per period costs of control will be equal to $p$. However, qualitative results would not change, if we assume any increasing and convex functional form.

\section{Proof:}

1. The proof of the first part of the proposition follows directly from Figure 3 . The social welfare in case cartel formation does not occur is given by $W_{(N E)}(p, \alpha)=$ $\frac{S D W L}{(1-\delta)}-p+0$. It does not depend on $\alpha$. Hence, the optimal policy to implement (NE) would just minimize $p$ and, hence, sets $p=p_{1}^{* *}$ and $\alpha \in\left[0, \alpha_{1}^{*}\right]$.

2. The proof of the second part is based on the idea that the solution of the maximization problem $\left\{\max _{p, \alpha}\left\{\frac{\delta S D W L}{1-\delta}-p+(1-\alpha) F\right\}\right.$ s.t. $V_{E S}>V_{N E}$ and

$\left.V_{E S}>V_{E N S}\right\}$ is given by the tangency point of the iso-welfare curve in case the (E S) outcome is implemented with the lowest incentive compatibility constraint for self-reporting to be profitable, i.e., $p_{2}^{*}(\alpha)$. See Fig. 4.

In this situation, two cases can arise: Firstly, if at the tangency point $p<p_{1}^{* *}$, the welfare, in case the (E S) outcome is implemented, is given by $W_{(E S)}(p, \alpha)=\frac{\delta S D W L}{(1-\delta)}-p+(1-\alpha) F$. Hence, the slope of the iso-welfare curve will be equal to $-\frac{\partial W_{(E S)}(p, \alpha) / \partial \alpha}{\partial W_{(E S)}(p, \alpha) / \partial p}=-F$, implying that the tangency point is determined by the solution of the following equation: $\left(p_{2}^{*}(\alpha)\right)_{\alpha}^{\prime}=-F$. See point $A$ in Fig. 4, where the dashed negatively sloped straight lines represent iso-welfare curves.

Secondly, if at the tangency point $p>p_{1}^{* *}$, we consider two corner solutions.

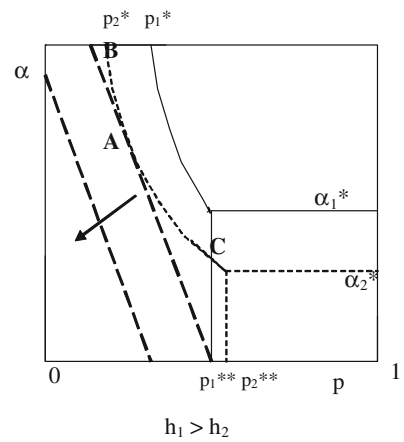

Fig. 4 Implementation of (ES) outcome 
The first is given by $p=p_{2}^{*}(1)$ and $\alpha=1$. This is illustrated by point $B$ in Fig. 4 . The welfare in this case is given by $W_{(E S)}\left(p_{2}^{*}(1), 1\right)=\frac{\delta S D W L}{(1-\delta)}-p_{2}^{*}(1)+0$

The second is given by $p=p_{1}^{* *}$ and $\alpha=\alpha^{*}$, where $\alpha^{*}: p_{2}^{*}=p_{1}^{* *}$. This is illustrated by point $C$ in Fig. 4. The welfare in this case is given by $W_{(E S)}\left(p_{1}^{* *}, \alpha^{*}\right)=\frac{\delta S D W L}{(1-\delta)}-p_{1}^{* *}+\left(1-\alpha^{*}\right) F$.

3. The third part of the proposition follows directly from Fig. 3 and the objective function of the antitrust authority: $W_{(E, N)}(p, \alpha)=\max _{p, \alpha}\left\{\frac{p \delta S D W L}{(1-\delta)}-\frac{p}{1-\delta}+p 2 F\right\}$.

Then, there are only corner solutions given by $p=0$ and $\alpha \in[0,1]$ if $\frac{\delta S D W L}{(1-\delta)}-$ $\frac{1}{1-\delta}+2 F<0$; and by $p=p_{1}^{* *}$ and $\alpha \in\left[0, \alpha^{*}\right.$ if $\frac{\delta S D W L}{(1-\delta)}-\frac{1}{1-\delta}+2 F \geq 0$. So, if gains to the society from conviction are low, it is reasonable not to control at all. And vise versa, if gains due to the savings of DWL and fines that can be collected are high, it is desirable for the antitrust authority to impose a strictly positive rate of law enforcement, $p=p_{1}^{* *}$.

\section{Appendix 4: Proof of the result in the Footnote 8}

In case leniency programs are present from $t=0$, the two-stage game described in Fig. 1 can be reduced to a one-stage game, where firms simultaneously choose between three possible strategies $(N E),(E, S)$, and $(E, N S)$. In this simultaneous move game, which is described in Table 2, there are no additional cartel profits realized in the first stage. This is the main difference with the two-stage game described in Fig. 1.

As before, we analyze the two different collusive strategy profiles (Enter Cartel and Self-report) and (Enter Cartel and Not Self-report) and one competitive strategy profile (Not to Enter the Cartel in the first place).

First, we consider the strategy Enter Cartel and Self-report $(E, S)$. If the firm decides to enter the cartel agreement and self-report, this may give $\frac{\pi_{n}}{1-\delta}-R h_{1}$ if the other member of cartel stays silent, $\frac{\pi_{n}}{1-\delta}-R h_{1}-\frac{(1-\alpha)}{2} F$ if the other firm also reports, or $\frac{\pi_{n}}{1-\delta}$ if the other firm decides not to enter cartel agreement. The second collusive strategy is Enter Cartel and Not Self-report $(E, N S)$. In this case the payoff, when the other member of the cartel also sticks to cartel agreement is determined recursively as an expectation of the monopoly gains, $\pi_{m}$, (if cartel is not found) and competitive profits, $\pi_{n}$, less the fine and losses due to asymmetric punishment effect

Table 2 Normal form of the simultaneous move stage game when LPs are present from $t=0$

\begin{tabular}{llll}
\hline firm 1 & firm 2 & & \\
\cline { 2 - 4 } & $N E,-$ & $E, S$ & $E S$ \\
\hline$N E,-$ & $\frac{\pi_{n}}{1-\delta}, \frac{\pi_{n}}{1-\delta}$ & $\frac{\pi_{n}}{1-\delta}, \frac{\pi_{n}}{1-\delta}$ & $\frac{\pi_{n}}{1-\delta}, \frac{\pi_{n}}{1-\delta}$ \\
$E, S$ & $\frac{\pi_{n}}{1-\delta}, \frac{\pi_{n}}{1-\delta}$ & $\frac{\pi_{n}}{1-\delta}-R h_{1}-\frac{(1-\alpha)}{2} F, \frac{\pi_{n}}{1-\delta}-R h_{2}-\frac{(1-\alpha)}{2} F$ & $\frac{\pi_{n}}{1-\delta}-R h_{1}, \frac{\pi_{n}}{1-\delta}-R h_{i}-F$ \\
$E, N S$ & $\frac{\pi_{n}}{1-\delta}, \frac{\pi_{n}}{1-\delta}$ & $\frac{\pi_{n}}{1-\delta}-R h_{1}-F, \frac{\pi_{n}}{1-\delta}-R h_{2}$ & $\frac{p\left(\frac{\pi_{n}}{1-\delta}-R h_{i}-F\right)+(1-p) \pi_{m}}{1-\delta+\delta p}, \frac{p\left(\frac{\pi_{n}}{1-\delta}-R h_{i}-F\right)+(1-p) \pi_{m}}{1-\delta+\delta p}$ \\
\hline
\end{tabular}


(if violation is discovered by the AA), i.e., $\frac{p\left(\frac{\pi_{n}}{1-\delta}-R h_{i}-F\right)+(1-p) \pi_{m}}{1-\delta+\delta p}$. Further, $(E, N S)$ strategy will lead to $\frac{\pi_{n}}{1-\delta}-R h_{1}-F$ if the other member of the cartel reports and $\frac{\pi_{n}}{1-\delta}$ if the other firm decides not to enter the cartel agreement. The competitive strategy profile Not to Enter the Cartel $(N E,-)$ implies that both firms obtain competitive profits $\pi_{n}$ forever, i.e., $\frac{\pi_{n}}{1-\delta}$.

Analysis of the payoffs in Table 2 reveals that the strategy $(E, S)$ is dominated by the strategy $(N E)$, since the discounted sum of profits if firms collude and self-report is always lower than the discounted sum of profits in case the cartel is not formed. Clearly, $\frac{\pi_{n}}{1-\delta}-R h_{i}-\frac{(1-\alpha)}{2} F<\frac{\pi_{n}}{(1-\delta)}$ for any possible parameters values $F, h_{i}, R \geq 0$ and $\alpha \in(0,1]$. So, we can say that further solution of the game should follow the same lines as described in Sects. 3 and 4 with the simplification that the strategy $(E, S)$ will not be played in equilibrium any more (for any possible parameter values).

We now proceed to analyze the subgame perfect equilibria of infinitely repeated game played among firms once the policy parameters and rules of leniency programs are set at $t=0$. For that, we have to compare the discounted sum of profits if firms form a cartel and the discounted sum of profits in case the cartel is not formed. This comparison has to be done for both cases, when firms choose to self-report and when they prefer not to cooperate with the Antitrust Authority.

First, we consider a setting where both firms choose the strategy Enter Cartel and Self-report, which we denote $(E, S)$. The expected payoff from playing this strategy for each firm includes the expected payoff from simultaneous self-reporting that is given by $V_{E, S}=\frac{\pi_{n}}{1-\delta}-R h_{i}-\frac{(1-\alpha)}{2} F .^{27}$ When no agreement about cartel formation is reached, the discounted payoffs for both firms, evaluated at $t=1$, are given by expression $V_{N E,-}=\frac{\pi_{n}}{(1-\delta)} \cdot{ }^{28}$ Collusion would arise if $V_{E S}>V_{N E,--}$ However, as discussed above, this inequality is never true, since $\frac{\pi_{n}}{1-\delta}-R h_{i}-\frac{(1-\alpha)}{2} F<\frac{\pi_{n}}{(1-\delta)}$ for all $R, h_{i}, F>0$. Hence, we can conclude that the collusive strategy:

Enter Cartel and Self-report will never arise, since it is dominated by the strategy: Not to Enter the Cartel for both firms. Hence, it can never arise in a SPNE. This proves the following Lemma.

Lemma 6 For given policy parameters $(F, f, p, \alpha)$, a subgame perfect equilibrium in which firms collude and self-report does not exist.

Hence, the normal form matrix game represented in Table 2 can be reduced to the game described in Table 3.

Next, we look at the second possible outcome, where both firms choose Not to Self-report.The expected payoff from playing this strategy is given by $V_{E, N S}=$ $\frac{p\left(\frac{\pi_{n}}{1-\delta}-R h_{i}-F\right)+(1-p) \pi_{m}}{1-\delta+\delta p}$. Again, when no agreement about cartel formation is reached, the discounted payoffs for both firms are given by expression $V_{N E,-}=\frac{\pi_{n}}{(1-\delta)}$.

\footnotetext{
27 To simplify the calculations, we evaluate all the payoffs at time $t=1$. So that, we discount payoffs obtained in periods $t>1$ into the first period with discount factor $\frac{1}{(1+r)^{t-1}}=\delta^{t-1}$.

${ }^{28}$ See Table 2.
} 
Table 3 The normal form of the simultaneous move game after dominated strategies are deleted

\begin{tabular}{lll}
\hline firm 1 & firm 2 & \\
\cline { 2 - 3 } & $N E,-$ & $E, N S$ \\
\hline$N E,-$ & $\frac{\pi_{n}}{1-\delta}, \frac{\pi_{n}}{1-\delta}$ & $\frac{\pi_{n}}{1-\delta}, \frac{\pi_{n}}{1-\delta}$ \\
$E, N S$ & $\frac{\pi_{n}}{1-\delta}, \frac{\pi_{n}}{1-\delta}$ & $\frac{p\left(\frac{\pi_{n}}{1-\delta}-R h_{i}-F\right)+(1-p) \pi_{m}}{1-\delta+\delta p}, \frac{p\left(\frac{\pi_{n}}{1-\delta}-R h_{i}-F\right)+(1-p) \pi_{m}}{1-\delta+\delta p}$ \\
\hline
\end{tabular}
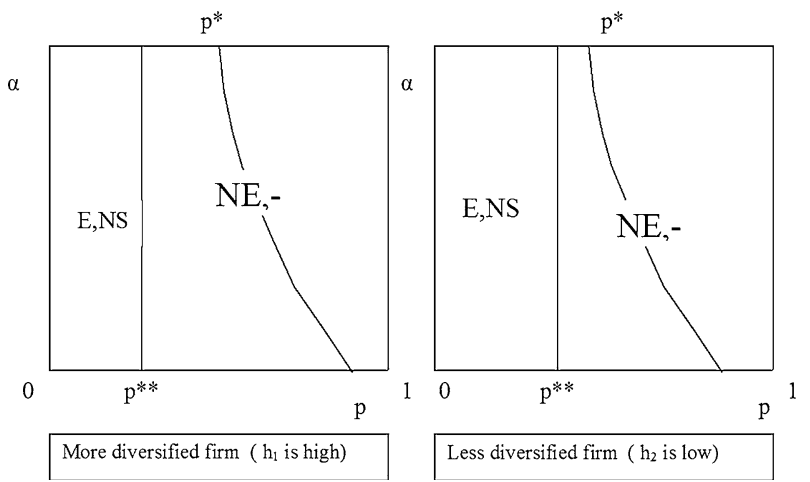

Fig. 5 Incentive compatibility constraints and Subgame Perfect Nash Equilibria when Leniency Programs are present from $t=0$

Looking at the Table 3, we can conclude that there are two Nash Equilibria in pure strategies. The strategy $(N E, N E)$ not enter the cartel for both firms is a Nash equilibrium of the normal form matrix game for any values of parameters of the model. However, the collusive equilibrium, in which both firms enter the cartel and do not self-report, can arise only if $V_{E, N S}>V_{N E \text {,-, }}$ that is, if the following condition is satisfied:

$$
p \leq \frac{\pi_{m}-\pi_{n}}{\pi_{m}-\pi_{n}+F+R h_{i}}=p^{* *}\left(F, h_{i}\right) \quad \text { for } i=1,2 .
$$

Note that when condition (9) is satisfied $((E, N S),(E, N S))$ would also be Paretodominant equilibrium of the matrix game in Table 3.

In order to establish when Enter and Not to Self-reportis a subgame perfect equilibrium, we have to consider only one constraint specified in (9). In Fig. 5, this constraint is represented by the vertical line $p^{* *}$. Threshold $p^{*}\left(F, h_{i}, \alpha\right)$ derived in Sect. 3.1, which specifies the values of the rate of law enforcement $p$ for which selfreporting is preferred to no self-reporting, is irrelevant in this setup due to Lemma 6 and the fact that the strategy $(E, S)$ is dominated by the strategy $(N E)$. This threshold is represented by the downward sloping locus $p^{*}$ in Fig. 5. Simple calculations also show that $p^{* *}\left(F, h_{i}\right)<p^{*}\left(F, h_{i}, \alpha\right)$ for any $F, h_{i}>0$ and for any $\alpha \in(0,1]$. Hence, we can conclude that the following Lemma holds. 
Lemma 7 For given policy parameters $(F, f, p, \alpha)$, a subgame perfect equilibrium in which firms enter the cartel and do not self-report exists if $p<p^{* *}\left(F, h_{i}\right) . A$ subgame perfect equilibrium in which firms do not enter the cartel in the first place exists if $p>p^{* *}\left(F, h_{i}\right)$.

Clearly, for a high rate of law enforcement, i.e., when $p>p^{* *}\left(F, h_{i}\right)$, the outcome with no collusion, $(N E, N E)$, where both firms decide to stay out of the cartel, is a SPNE of the game. Fig. 5 illustrates the equilibrium solutions stated in Lemma 7 for the two firm types.

End of the proof of Footnote 8

This analysis shows that the solution of the game, in case leniency programs are present from $t=0$, follows the same lines as described in Sects. 3 and 4 with the simplification that the strategy $(E, S)$ will not be played in equilibrium any more (for any possible parameter values) as discussed in the Footnote 8.

\section{Appendix 5: Comparison of leniency programs in the US and Europe}

We can stress two main aspects in which the sentencing guidelines and the applications of leniency programs differ among different countries: The timing of introduction of leniency programs and competition law in general and Optimality

Table 4 Fining systems and structure of leniency programs

\begin{tabular}{|c|c|c|c|c|c|}
\hline Country & Size of fine & Limitation of fine & $\begin{array}{l}\text { Number } \\
\text { of fine } \\
\text { reduct. }\end{array}$ & $\begin{array}{l}\text { Max fine } \\
\text { reduction } \\
\text { first } \\
\text { reporter } \\
(\%)\end{array}$ & $\begin{array}{l}\text { Max fine } \\
\text { reduction } \\
\text { other } \\
\text { reporters }\end{array}$ \\
\hline EU & $\begin{array}{l}\text { Base level of fine is determined } \\
\text { by gravity and duration }\end{array}$ & $\begin{array}{l}10 \% \text { of total } \\
\text { annual turnover } \\
\text { of year before } \\
\text { conviction }\end{array}$ & $>1$ & 100 & Up to $50 \%$ \\
\hline US & $\begin{array}{l}\text { Fine is determined on the basis } \\
\text { of gravity, illegal gains from } \\
\text { offense, and damage to } \\
\text { society }\end{array}$ & No upper bound & 1 & 100 & $\begin{array}{l}\text { No fine } \\
\text { reduction }\end{array}$ \\
\hline UK & $\begin{array}{l}\text { Seriousness and relevant } \\
\text { turnover form a basis }\end{array}$ & $\begin{array}{l}10 \% \text { of total UK } \\
\text { turnover of year } \\
\text { before } \\
\text { conviction }\end{array}$ & $>1$ & 100 & $50 \%$ \\
\hline NL & $\begin{array}{l}\text { A base fine of } 10 \% \text { of the } \\
\text { estimated illegal gains }\end{array}$ & $\begin{array}{l}10 \% \text { of total } \\
\text { annual turnover } \\
\text { of year before } \\
\text { conviction }\end{array}$ & $>1$ & 100 & $40 \%$ \\
\hline Germany & $\begin{array}{l}\text { Seriousness and duration form } \\
\text { a basis }\end{array}$ & $\begin{array}{l}10 \% \text { of total } \\
\text { annual turnover } \\
\text { of year before } \\
\text { conviction }\end{array}$ & $>1$ & 100 & $50 \%$ \\
\hline
\end{tabular}


Table 5 Timing of introduction of competition law and leniency programs

\begin{tabular}{llllll}
\hline \multicolumn{2}{l}{ General competition law } & & & \multicolumn{2}{l}{ Leniency program } \\
\cline { 1 - 1 } Country & First initiative & Organization in charge & & LP introduction & LP latest revision \\
\hline EU & 1959 & Commission & & 1996 & 2006 \\
US & 1890 & DoJ & & 1978 & 1997 \\
UK & 1998 & Office of Fair Trading & & 1998 & 2004 \\
Netherlands & 1998 & Nma & & 2002 & 2007 \\
Germany & 1958 & Bundeskartellamt & & 2002 & 2006 \\
\hline
\end{tabular}

Table 6 Determination of the fine for UCAR according to the EC guidelines

\begin{tabular}{ll}
\hline $\begin{array}{l}\text { Fine after each stage in } \\
\text { mil. } €\end{array}$ & Base fine \\
\hline 40 & $\begin{array}{l}\text { Gravity: very serious infringement } \\
\text { Duration: } 5 \text { years and } 9 \text { months, implying an increase of } 55 \% \text { of the amount } \\
\text { determined according to gravity and result in a base fine of } € 62 \text { million. }\end{array}$ \\
\hline 62 & Individual fine \\
\hline 99.2 & Aggravating factors imply an increase of $60 \%$ of the base fine \\
50.1 & $\begin{array}{l}\text { Reduction of fine due to the max limit of fines (10\% of overall turnover) } \\
40 \% \text { reduction due to application of leniency policy }\end{array}$ \\
50.4 & Total fine \\
\hline
\end{tabular}

considerations such as the size of the fine and the number of reductions. These results are summarized in the Tables 4 and 5 below. Sources: EC (2006a, b), NMa (2007), DOJ (1993), DOJ (2008), OECD (2002).

\section{An example of a fining decision ${ }^{29}$}

The determination of the fine by the Commission for the European part of the graphite electrode cartel, UCAR International, is described in Table 6 (this figure is adopted from Wehmhoerner 2005). The nature of the infringement was deemed to be very serious, because UCAR had engaged in market-sharing and price-fixing practices, which were implemented with full knowledge of the illegality of the actions. In considering the actual impact of the infringement, the decision notes that during the time of the cartel agreement, prices nearly doubled. Moreover, the producers represented almost $90 \%$ of the worldwide market, and the prices were not only agreed but also announced and implemented. Hence, the amount of the fine according to gravity for the two main producers, UCAR and SGL, was selected to be 40 million euro.

Aggravating factors included UCAR's role as one of the ringleaders and instigators of the cartel and the continuation of the infringement after the

\footnotetext{
29 This example is adopted from Wehmhoerner (2005).
} 
Table 7 Determination of the fine for UCAR according to the US guidelines

\begin{tabular}{|c|c|c|}
\hline $\begin{array}{l}\text { Fine in US \$ mil } \\
\text { after each step }\end{array}$ & $\begin{array}{l}\text { Culpability } \\
\text { score }\end{array}$ & Base fine \\
\hline \multirow[t]{5}{*}{142.6} & & $\begin{array}{l}20 \% \text { of the volume of commerce of US } \$ 713 \text { million of UCAR's } \\
\text { US sales between July 1992-June } 1997\end{array}$ \\
\hline & & Aggravating and attenuating factors \\
\hline & +5 & Starting point as fixed in the guidelines \\
\hline & +4 & 1000 employees and high-level personnel involved. \\
\hline & -2 & Acceptance of responsibility and full cooperation. \\
\hline 199.64 to 399.28 & $=7$ & $\begin{array}{l}\text { Culpability score of } 7 \text { implies a min multiplier of } 1.40 \text { ( } 40 \% \\
\text { increase in the base fine) and a maximum multiplier of } 2.80 \\
\text { ( } 180 \% \text { increase in the base fine), yielding a fining range of US } \\
\$ 199.64 \text { to US } \$ 399.28 \text { million. }\end{array}$ \\
\hline 110 & & $\begin{array}{l}\text { Alternative fine because of UCAR's inability to pay ( } 15.4 \% \text { of US } \\
\text { volume of commerce) }\end{array}$ \\
\hline
\end{tabular}

investigation started. Although UCAR was not the first company that provided the Commission with decisive evidence, it contributed substantially to establishing important aspects of the case and the Commission, therefore, granted a reduction of $40 \%$ of the fine.

To provide an overview of the fining method behind the US guidelines, the application of the guidelines in the determination of the fine for the US part of the graphite electrode cartel, UCAR International, is described in Table 7 (this figure is adopted from Wehmhoerner 2005). UCAR was accused of price-fixing in the US from 1992 to 1997. The memorandum was filed in April 1998 by the District Court for the Eastern District of Pennsylvania.

The fining range is determined by calculating $20 \%$ of the volume of affected commerce over the entire duration as a starting fine. Subsequently, for each factor, such as the size of the undertaking in terms of the number of employees, the corresponding points with which to increase or decrease the culpability score can be read from the guidelines. There is a direct quantitative link between these factors and the fining range through the use of the culpability score, which determines the fining range. However, neither the guidelines nor the decision explain how the alternative fine should be determined in case of inability to pay.

\section{References}

Apesteguia J, Dufwenberg M, Selten R (2007) Blowing the whistle. Econ Theory 31(1):143-166

Becker G (1968) Crime and punishment: an economic approach. J Polit Econ 76:169-217

Chen J, Harrington J (2007) The impact of the corporate leniency program on cartel formation and the cartel price path. In: Ghosal V, Stennek J (eds) The political economy of antitrust. Elsevier, New York

Chen Z, Rey P (2007) On the design of leniency programs. IDEI working papers 452, Institut d'conomie Industrielle (IDEI), Toulouse

DOJ (1993) US Corporate Leniency Policy. http://www.usdoj.gov/atr/public/guidelines/ 
DOJ (2008) US sentencing guidelines (chapter 8: sentencing of organizations)

EC (2006a) Commission Notice on immunity from fines and reduction of fines in cartel cases. Off J Eur Union (2006/C 298/11), Brussels

EC (2006b) Guidelines on the method of setting fines imposed pursuant to Article 23(2)(a) of Regulation No 1/2003. Off J Eur Union (2006/C 210/02), Brussels

Ellis C, Wilson W (2003) Cartels, price-fixing, and corporate leniency policy: what doesn't kill us makes us stronger. mimeo, University of Oregon, Oregon

Feess E, Walzl M (2003) Corporate leniency programs in the EU and the USA. German working papers in law and economics 2003-1-1077, 24

Fundenberg D, Tirole J (1991) Game theory. MIT, Cambridge

Garoupa N (2001) Optimal magnitude an probability of fines. Eur Econ Rev 45:1765-1771

Harrington J (2008) Optimal corporate leniency programs. J Ind Econ LVI(2):215-246

Hinloopen J (2003) An economic analysis of leniency programs in antitrust law. Economist 151:415-432

Hinloopen J (2006) Internal Cartel stability with time-dependent detection probabilities. Int J Ind Organ 24(6):1213-1229

Houba H, Motchenkova E, Wen Q (2008) Maximal Cartel pricing and leniency programs. Tinbergen Institute discussion papers 08-120/1, Tinbergen Institute

Innes R (1999) Remediation and self-reporting in optimal law enforcement. J Pub Econ 72:379-393

Kaplow L, Shavell S (1994) Optimal law enforcement with self-reporting of behavior. J Polit Econ 102:583-605

Malik A (1993) Self-reporting and the design of policies for regulating stochastic pollution. J Environ Econ Manag 24:241-257

Miller N (2009) Strategic leniency and cartel enforcement. Am Econ Rev 99(3):750-768

Motchenkova E (2004) Effects of leniency programs on cartel stability. CentER discussion papers series 2004-98, Tilburg University, Tilburg

Motchenkova E (2008) Determination of optimal penalties for antitrust violations in a dynamic setting. Eur J Oper Res 189(1):296-291

Motchenkova E, Kort P (2006) Analysis of the properties of current penalty schemes for violations of antitrust law. J Optim Theory Appl 128(2)

Motta M, Polo M (2003) Leniency programs and cartel prosecution. Int J Ind Organ 21:347-379

$\mathrm{NMa}(2007) \mathrm{NMa}$ fining code and leniency guidelines. http://www.nmanet.nl/

OECD (2002) Fighting hard core cartels: harm, effectiveness of sanctions and leniency programmes, Paris. http://www.oecd.org/dataoecd/41/44/1841891.pdf

Rey P (2003) Towards a theory of competition policy. In: Dewatripont M, Hansen L, Turnovsky S (eds) Advances in economics and econometrics: theory and applications. Cambridge University Press, Cambridge

Spagnolo G (2004) Optimal leniency programs. Center for Economic Policy Research, Discussion paper series, 4840, http://www.cepr.org/pubs/new-dps/showdp.asp?dpno=4840, (re-vised2008)

Wehmhorner N (2005) Optimal fining policies. Paper presented at the remedies and sanctions in competition policy conference, Amsterdam Center for Law and Economics 